Elizabeth BOHLAND ${ }^{1}$

Vanessa de Moura SÁ$\mathrm{ROCHA}^{1}$

Fernanda Cavallini

CYRILLO $^{1}$

Fernando José BENESI ${ }^{1}$

Correspondência para:

Av. Prof. Dr. Orlando Marques de Paiva, 87

Cidade Universitária

São Paulo/SP, 05508-000

Recebido para publicação: 20/03/2007 Aprovado para publicação: 25/10/2007

\title{
Efeito do tempo de conservação de polimorfonucleares do sangue de bezerros sobre 0 metabolismo oxidativo e a atividade de fagocitose de Escherichia coli
}

1 - Faculdade de Medicina Veterinária e Zootecnia da Universidade de São Paulo, São Paulo - SP

\section{Resumo}

Foram avaliados os efeitos do tempo sobre o metabolismo oxidativo e a fagocitose de Escherichia coli, em amostras de polimorfonucleares (PMN) do sangue, de cinco bezerros hígidos, conservadas em banho de gelo por duas (t2), quatro (t4), seis (t6), 12 (t12) e 24 (t24) horas. O metabolismo oxidativo foi avaliado utilizando o Diacetato 2' 7' Diclorofluoresceína (DCFH-DA) e a E. coli, como estímulo. Para a fagocitose a mesma bactéria foi utilizada. As amostras foram analisadas por citometria de fluxo. O metabolismo oxidativo basal dos PMN do sangue de bezerros foi maior nos tempos t4, t6 e t12, do que em t2 $(\mathrm{p}<0,05)$. A intensidade de fluorescência do metabolismo oxidativo induzido pela bactéria foi maior nos tempos t4 e t6 do que em t2 $(p<0,05)$. A comparação entre o metabolismo basal e induzido pela bactéria, em cada um dos tempos, mostrou que a maior diferença ocorreu em t2, com valores da média geométrica e desvios padrão respectivos de 18,3 $\pm 4,4$ e 26,7 $\pm 1,8(\mathrm{p}<0,05)$. A atividade de fagocitose, medida pela intensidade de fluorescência, foi maior para as amostras mantidas em gelo por 6 horas do que para $\mathrm{t} 2$, t 4 e t12 $(p<0,05)$. O percentual de fagocitose não diferiu entre os tempos. O tempo ideal para análise do metabolismo oxidativo foi o de duas horas. Maiores estudos são necessários para se verificar a influência do tempo de conservação na fagocitose de E. coli por PMN do sangue de bovinos.

\section{Introdução}

A citometria de fluxo é uma técnica emergente na Medicina Veterinária que permite uma análise rápida e objetiva de células em suspensão. ${ }^{1}$ Esta técnica, muito utilizada na avaliação da função de polimorfonucleares (PMN) do sangue em várias espécies animais e no homem, oferece uma análise quantitativa de uma variedade de tipos celulares baseada no tamanho da célula, complexidade molecular e composição antigênica. Assim, este método de análise complementa e amplia os conhecimentos obtidos com a microscopia óptica. ${ }^{2}$ A avaliação funcional dos PMN do sangue é normalmente realizada através da mensuração do metabolismo oxidativo e da atividade de fagocitose destas células. ${ }^{3}$

As amostras de sangue devem ser processadas e analisadas o mais breve possível, já que o processo de estocagem da amostra é um ponto chave na obtenção de resultados precisos, sendo recomendado que as amostras sejam refrigeradas e processadas dentro de quatro horas após a colheita de sangue a fim de se evitar resultados falsos ou inconclusivos. ${ }^{2}$ Segundo Vuorte, Jansson e Repo ${ }^{4}$, na oxidação do Diacetato 2' 7' Diclorofluoresceína (DCFH), a manutenção da integridade de membrana e da viabilidade celular em todos os estágios de preparação das células é essencial para se evitar a saída do substrato ou de seus derivados 
fluorescentes, o que poderia resultar na ocorrência de subgrupos de células com uma falsa redução da intensidade de fluorescência.

Em se tratando da espécie bovina, podem se tornar um entrave a localização do citômetro em grandes centros urbanos e o tempo decorrido da colheita de sangue até a análise das funções celulares. Trabalhos, nessa espécie animal, avaliando contagem total de leucócitos, a atividade de fagocitose e o metabolismo oxidativo de PMN do sangue mostram variações no tempo de processamento das amostras que se colocam entre duas a seis horas. ${ }^{5,6,7}$

Visando avaliar os efeitos do tempo sobre a atividade funcional de PMN do sangue de bezerros, foi elaborado este estudo, com o objetivo de se estabelecer um limite de tempo no qual as amostras deverão ser colhidas e analisadas, sem que haja prejuízos na atividade funcional destas células. Para tal, foram avaliados o metabolismo oxidativo e a fagocitose de Escherichia coli, em amostras de PMN do sangue de bezerros mantidos em banho de gelo em diferentes períodos de tempo.

\section{Material e Método}

Foram utilizados cinco bezerros clinicamente hígidos, machos e fêmeas, com idade entre quatro e dez meses, sendo colhidos 10,0 $\mathrm{ml}$ de sangue da veia jugular; $5,0 \mathrm{ml}$ em tubo à vácuo contendo heparina sódica e $5,0 \mathrm{ml}$ em tubos à vácuo com EDTA sódico. Imediatamente após a colheita, as amostras foram armazenadas em caixas de isopor contendo gelo picado, sendo mantidas nestas condições até o momento da análise.

As amostras com EDTA foram utilizadas para a realização do leucograma, contagens total e diferencial de células para que se pudesse estimar o número de PMN das amostras.

O sangue colhido com heparina foi mantido em banho de gelo, antes do processamento, nos momentos a seguir: duas horas (t2), quatro horas ( $\mathrm{t} 4)$, seis horas (t6), doze horas (t12) e vinte e quatro horas (t24), para a avaliação do metabolismo oxidativo de PMN do sangue de bezerros e da atividade de fagocitose para a Escherichia coli e, utilizando-se os reagentes e as metodologias descritas a seguir.

\section{Reagentes}

Solução de Diacetato 2' 7' Diclorofluoresceína (DCFH-DA / Molecular Probes, Eugene, OR) (mantida a $-20^{\circ} \mathrm{C}$, protegida da luz). No momento do uso, a solução estoque ( $25 \mathrm{mM}$ diluída em etanol) foi diluída em PBS de forma que o volume final desta solução fosse o suficiente para realizar o experimento, segundo as recomendações de Silva ${ }^{8}$ e Massoco-Salles Gomes?.

Escherichia coli (cepa k-12) (Bio Particlesâ, conjugada com Texas Redâ (E2863) / Molecular Probes, Eugene, OR). As bactérias foram reconstituídas em um tubo de vidro em concentração de $20 \mathrm{mg} / \mathrm{ml}$, usando-se um tampão de PBS estéril com $2 \mathrm{mM}$ de azida de sódio, conforme as recomendações do protocolo da Molecular Probes.â. As bactérias ressuspendidas em PBS foram aliquotadas em volumes de $500 \mathrm{ml}$ (aprox. 3,0 × $10^{8}$ bactérias), em microtubos de 2,0 $\mathrm{ml}$, protegidas da luz, identificadas e congeladas a uma temperatura de $-80^{\circ} \mathrm{C}$. Imediatamente antes do uso as alíquotas de bactérias eram descongeladas e as concentrações ajustadas relativamente ao número de PMN do sangue na concentração de aproximadamente 200 bactérias/PMN.

\section{Avaliação do metabolismo oxidativo e da atividade de fagocitose $E$. coli por PMN de bezerros}

O metabolismo oxidativo e a fagocitose foram avaliados para todos os animais utilizados, segundo a metodologia proposta por Hasui, Hirabayashi e Yohnosuke $^{10}$ e aplicada por Silva ${ }^{8}$ e Massoco-Salles Gomes ${ }^{9}$, nos tempos: $\mathrm{t} 2$, t4, t6, t12 e t24.

O metabolismo oxidativo basal de PMN foi avaliado usando-se $100 \mathrm{ml}$ de sangue total heparinizado, $200 \mathrm{ml}$ de DCFHDA $(0,3 \mathrm{mM})$ e PBS q.s.p. 1,0 ml. O 
metabolismo oxidativo de PMN estimulados pela bactéria foi avaliado pela adição de $100 \mathrm{ml}$ de sangue total heparinizado, $200 \mathrm{ml}$ de DCFH-DA $(0,3$ $\mathrm{mM}), 100 \mathrm{ml}$ de E. coli conjugada com Texas Red e PBS q.s.p. 1,0 ml. Para a avaliação da atividade de fagocitose foram utilizados $100 \mathrm{ml}$ de sangue total heparinizado, $100 \mathrm{ml}$ de E. coli conjugada com Texas Red e PBS q.s.p. $1,0 \mathrm{ml}$.

As amostras assim preparadas foram colocadas em banho-maria à $37^{\circ} \mathrm{C}$ sob agitação, durante 30 minutos. As reações foram interrompidas pela adição de 2,0 $\mathrm{ml}$ de solução de EDTA gelada $(3 \mathrm{mM})$. As amostras foram centrifugadas por 10 minutos a $250 \mathrm{~g}$ e as hemácias removidas dos botões de leucócitos do sangue periférico por lise hipotônica com uma solução de $\mathrm{NaCl}$ a $0,2 \%$ por 20 segundos. Imediatamente após esta lise, foram colocados 2,0 $\mathrm{ml}$ de uma solução de $\mathrm{NaCl}$ a $1,6 \%$ em cada amostra, com o objetivo de restaurar a isotonicidade. As amostras foram centrifugadas novamente, sendo desprezado o sobrenadante. Repetiu-se a lise hipotônica, sendo os tubos centrifugados pela última vez e o sobrenadante desprezado. Os botões celulares obtidos foram ressuspensos em 1,0 $\mathrm{ml}$ de PBS para a análise no citômetro de fluxo.

Desta forma, em cada um dos tempos estudados, o experimento apresentava a seguinte bateria de tubos, para cada animal (Quadro 1).

\section{Leitura das amostras no Citômetro de Fluxo}

Após a etapa descrita foi realizada a leitura das amostras no citômetro de fluxo (Facscan Calibur Becton Dickinson Immunocytometry System, San Jose, CA, USA) conectado a um computador (Macintosh Apple, $C A, U S A$ ) utilizando o software Cell Quest (Becton Dickinson Immunocytometry System, San Jose, CA, USA) do Laboratório de Farmacologia e Toxicologia do Departamento de Patologia da Faculdade de Medicina Veterinária e Zootecnia da Universidade de São Paulo. Foram adquiridos 10.000 eventos de cada amostra. Os resultados de fluorescência foram gravados em uma escala logarítmica. A fluorescência verde do DCFH-DA foi mensurada a $530 \pm 30 \mathrm{~nm}$ (FL1) e a fluorescência vermelha da E.coli conjugada com Texas Red foi medida a $585 \pm 42 \mathrm{~nm}$ (FL2).

Os dados gerados no citômetro foram analisados com auxílio do software WinMDI 2.8 (Joseph Trotter, Scripps Research Institute, La Jolla, California, US A $)^{11}$. Os valores referentes à atividade de fagocitose e ao metabolismo oxidativo foram estimados pela média geométrica da intensidade de fluorescência emitida pelos PMN. O percentual de fagocitose foi calculado pela fórmula:

$$
\text { Porcentagem de fagocitose }=\frac{\text { número de PMN que fagocitaram }}{\text { número total de PMN }} \times 100
$$

Análise estatística

Para avaliação da atividade de

\begin{tabular}{|c|c|c|c|c|}
\hline Tubo & Sangue total & DCFH - DA & Ecoli + T.R. & PBS \\
\hline A (controle negativo) & $100 \mu 1$ & - & - & $900 \mu \mathrm{l}$ \\
\hline $\begin{array}{l}\text { B (metab. oxidativo } \\
\text { basal) }\end{array}$ & $100 \mu \mathrm{l}$ & $200 \mu \mathrm{l}$ & - & $700 \mu \mathrm{l}$ \\
\hline $\mathrm{C}$ (metab. induz. E. coli) & $100 \mu 1$ & $200 \mu \mathrm{l}$ & $100 \mu \mathrm{l}$ & $600 \mu \mathrm{l}$ \\
\hline $\begin{array}{l}\mathrm{D} \text { (atividade de } \\
\text { fagocitose) }\end{array}$ & $100 \mu \mathrm{l}$ & - & $100 \mu \mathrm{l}$ & $800 \mu \mathrm{l}$ \\
\hline
\end{tabular}

Quadro 1 - Exemplo da bateria de tubos utilizados para avaliar a atividade funcional de polimorfonucleares do sangue de bezerros neonatos "in vitro". São Paulo - 2006 
metabolismo oxidativo basal e induzido pela E. coli, e da atividade fagocítica dos PMN contra E.coli foi utilizada a análise de variância ( $A N O V A)$ complementada pelo teste de Tukey-Kramer para múltiplas comparações. Para a comparação do metabolismo oxidativo basal e induzido pela E. coli em cada um dos tempos do estudo foi utilizado o teste de Bartlett p'ara testar a homogeneidade das variâncias seguido do teste $t$ de Student ${ }^{12}$. Os dados foram analisados pelo StatsDirect Statistical Ltd ${ }^{13}$. Para todas as análises foi considerado um nível de significância menor que 5\%.

\section{Resultados}

O metabolismo oxidativo basal dos PMN do sangue de bezerros foi significativamente $(\mathrm{p}<0,05)$ maior nos tempos 44 , t6 e t12, quando comparado com o tempo t2 do estudo. As amostras dos tempos $\mathrm{t} 4$, t6 e t12 comparadas entre si, não mostraram diferenças, conforme se observa na tabela 1 e na figura $1 . \mathrm{Na}$ figura 2, apresentam-se os "dot plots" obtidos durante a aquisição dos dados de uma amostra de sangue do tempo t2, onde se pode observar a população de PMN utilizada na análise dos dados. Pode-se observar que as células aumentam de tamanho quando o metabolismo oxidativo é induzido pela bactéria (vide deslocamento da posição da população R1 à direita no eixo $\mathrm{x}$, referente à propriedade FSC- Forward side scatter que indica o tamanho da célula) mostrando que durante a fagocitose ocorre alteração na morfologia celular e que a técnica de citometria de fluxo é capaz de verificar esta modificação.

Tabela 1 - Valores das médias geométricas e respectivos desvios-padrão da intensidade de fluorescência obtida na análise do metabolismo oxidativo espontâneo (basal) (cel + DCFH) e induzido pela $E$. coli marcada pelo Texas Red (cel + DCFH + E. coli) de PMN do sangue de bezerros, segundo o tempo em que as amostras foram mantidas em gelo picado até o processamento. São Paulo - 2006

\begin{tabular}{ccc}
\hline Tempo de conservação & cel + DCFH & cel + DCFH + E. coli \\
\hline t2 & $18,3 \pm 4,4^{\mathrm{aA}}$ & $26,7 \pm 1,8^{\mathrm{cB}}$ \\
t4 & $39,1 \pm 7,1^{\mathrm{b}}$ & $43,5 \pm 8,3 \mathrm{~d}$ \\
t6 & $36,8 \pm 7,1^{\mathrm{b}}$ & $40,1 \pm 6,6 \mathrm{~d}$ \\
t12 & $33,1 \pm 8,7 \mathrm{~b}$ & $32,7 \pm 7,2 \mathrm{c}, \mathrm{d}$ \\
\hline
\end{tabular}

letras minúsculas diferentes na mesma coluna, resultados significantes $(\mathrm{p}<0,05)$

letras maiúsculas diferentes na mesma linha, resultados significantes $(p<0,05)$

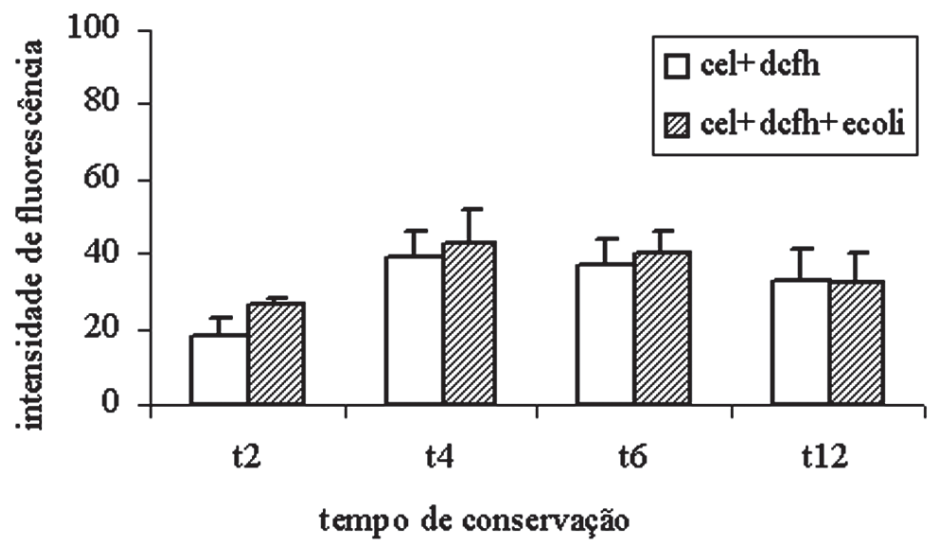

Figura 1 - Efeito do tempo de conservação das amostras em banho de gelo sobre a intensidade de fluorescência obtida na análise do metabolismo oxidativo basal (cel + DCFH) e induzido pela E.coli (cel + DCFH + E. coli). São Paulo - 2006 


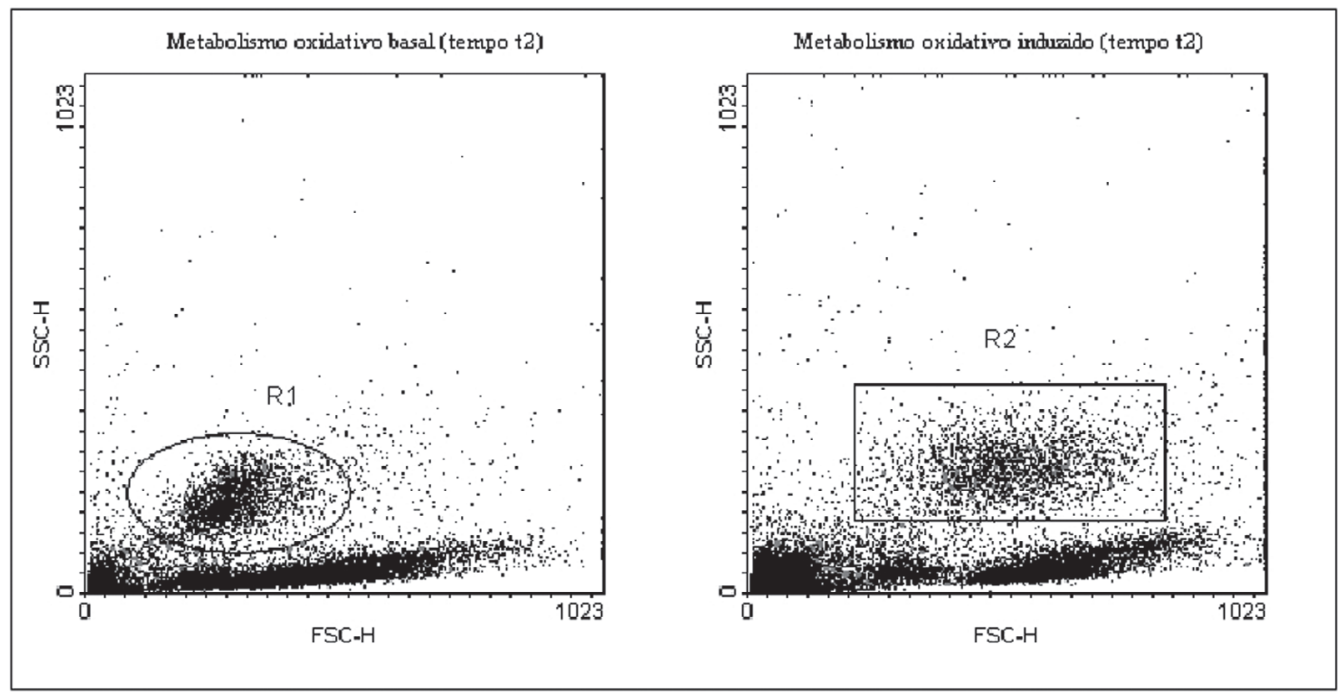

Figura 2 - Citogramas de leucócitos do sangue de bezerro mantidos por 2 horas em banho de gelo picado até o processamento; R1: PMN incubados com DCFH; R2: PMN incubados com DCFH + E.coli. São Paulo - 2006

A análise estatística das médias geométricas da intensidade de fluorescência do metabolismo oxidativo de PMN do sangue de bezerros induzido pela E. coli. (Tabela 1 e Figura 1) revela que o maior valor foi encontrado para as amostras analisadas nos tempos t4 e t6 sendo significativamente maiores $(p<0,05)$, quando comparadas com as amostras analisadas no tempo t2.

A comparação entre as médias geométricas da intensidade de fluorescência avaliada separadamente entre cada um dos tempos de estudo mostrou diferença significativa $(p<0,05)$ entre o metabolismo oxidativo basal e o induzido pela E. coli no tempo de duas horas após a colheita do sangue dos bezerros (t2). Com o passar do tempo esta diferença deixa de existir (Figura 1). O tempo t 24 foi excluído da análise, devido a grande alteração morfológica apresentada pelas células no "dot plot", inviabilizando sua avaliação conforme pode ser verificado pelos citogramas mostrados na figura 3 .

A atividade de fagocitose (Figura 4), medida pela média geométrica da intensidade de fluorescência, foi significativamente maior $(\mathrm{p}<0,05)$ para a população de PMN do sangue mantidos em banho de gelo por 6 horas quando comparada aos demais tempos (Tabela 2).
No entanto, a avaliação do percentual de fagocitose de PMN do sangue para a E.coli marcada pelo Texas Red não mostrou diferenças entre os tempos estudados (Tabela 2, Figura 5). O momento t 24 foi excluído da análise, pelos mesmos motivos apresentados anteriormente.

\section{Discussão}

A análise dos resultados deste trabalho mostra, no que se refere à comparação do metabolismo oxidativo basal e aquele induzido pela bactéria, que as maiores diferenças foram obtidas quando as amostras eram analisadas após a conservação em banho de gelo por duas horas.

Os valores das médias geométricas da intensidade de fluorescência para o metabolismo basal e induzido pela bactéria, não diferiram entre si, exceto no tempo t2.

Resultados semelhantes ao deste estudo, foram encontrados por Zhao et al. ${ }^{14}$, que ao analisarem o metabolismo oxidativo de neutrófilos basal e estimulado por PMA (Miristato-acetato de forbol), fMLP (Nformil-metionil-leucil-fenilalanina) e E.coli, e duas concentrações diferentes de propofol em seres humanos, não verificaram diferenças entre as amostras do grupo controle e dos tratamentos quando a E.coli 


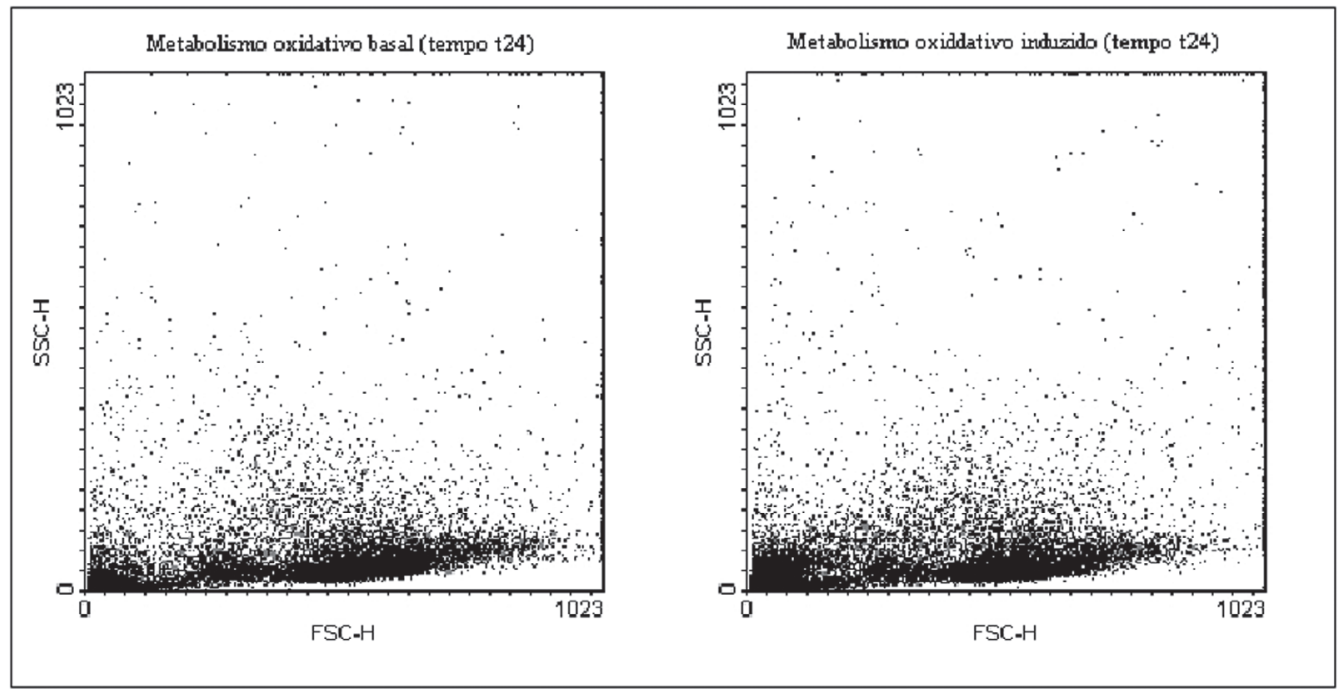

Figura 3 - Citogramas do metabolismo oxidativo basal (cel + DCFH) e induzido (cel + DCFH + E.coli) de leucócitos de bezerros mantidos por 24 horas em banho de gelo antes da análise. São Paulo - 2006

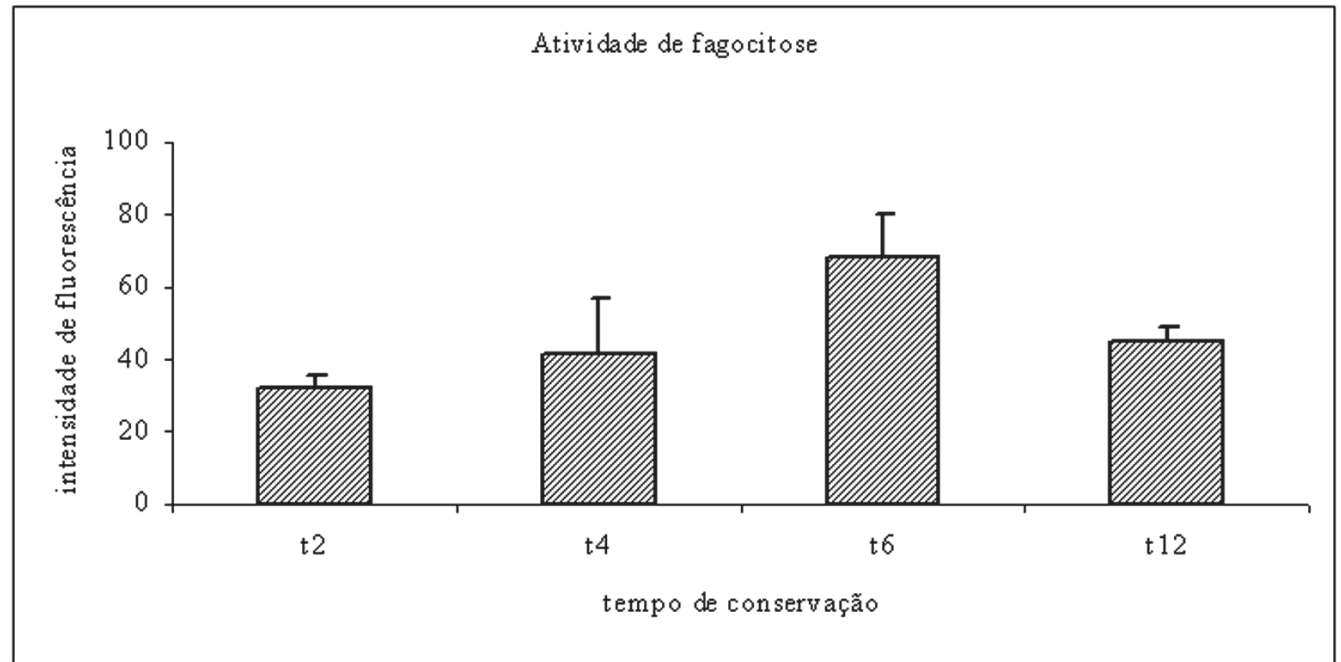

Figura 4 - Efeito do tempo em que as amostras foram mantidas em banho de gelo sobre a média geométrica da intensidade de fluorescência de PMN em atividade de fagocitose (cel + E.coli). São Paulo - 2006

foi utilizada como estímulo. Tal fato pode ser explicado pelas diferenças de ativação do metabolismo oxidativo quando utilizada a E. coli, uma vez que é necessário que ocorra fagocitose, ao passo que outros estímulos, como o fMLP e a Yersinia enterocolitica ativam o metabolismo oxidativo por ligação em receptores de membrana destas células e o PMA é um ativador direto da proteína quinase $\mathrm{C}(\mathrm{PKC}){ }^{4}$

No método de oxidação do DCFH, a perda de integridade de membrana e da viabilidade celular poderia resultar na ocorrência de subgrupos de células com uma falsa redução da intensidade de fluorescência do $\mathrm{DCFH}^{4}$ podendo estar associada a apoptose e necrose celular, fato que provavelmente ocorreu no tempo t 24 .

Em relação à atividade de fagocitose, foi verificado que o seu percentual se manteve constante, durante os diferentes tempos de análise. Entretanto, a intensidade de fluorescência medida pela média geométrica foi maior no momento t6, não havendo diferenças significantes entre os demais tempos. Sabe-se que a intensidade de 
Tabela 2 - Valores das médias geométricas e desvios-padrão da intensidade de fagocitose obtida pela intensidade média de fluorescência estimulada pela $E$. coli marcada pelo Texas Red e do percentual de fagocitose de PMN do sangue de bezerros, segundo o tempo que as amostras foram mantidas em gelo picado até serem analisadas. São Paulo - 2006

\begin{tabular}{ccc}
\hline Tempo de conservação & cel+E coli & \% de fagocitose \\
\hline t2 & $31,5 \pm 3,8^{\mathrm{a}}$ & $40,3 \pm 7,9^{\mathrm{c}}$ \\
$\mathrm{t} 4$ & $41,2 \pm 15,6^{\mathrm{a}}$ & $37,4 \pm 7,4^{\mathrm{c}}$ \\
$\mathrm{t} 6$ & $67,9 \pm 12,0^{\mathrm{b}}$ & $47,1 \pm 10,4^{\mathrm{c}}$ \\
$\mathrm{t} 12$ & $45,2 \pm 3,5^{\mathrm{a}}$ & $46,4 \pm 9,0^{\mathrm{c}}$
\end{tabular}

letras minúsculas diferentes na mesma coluna, resultados significantes $\mathrm{p}<0,05$

letras maiúsculas diferentes na mesma linha, resultados significantes $\mathrm{p}<0,05$

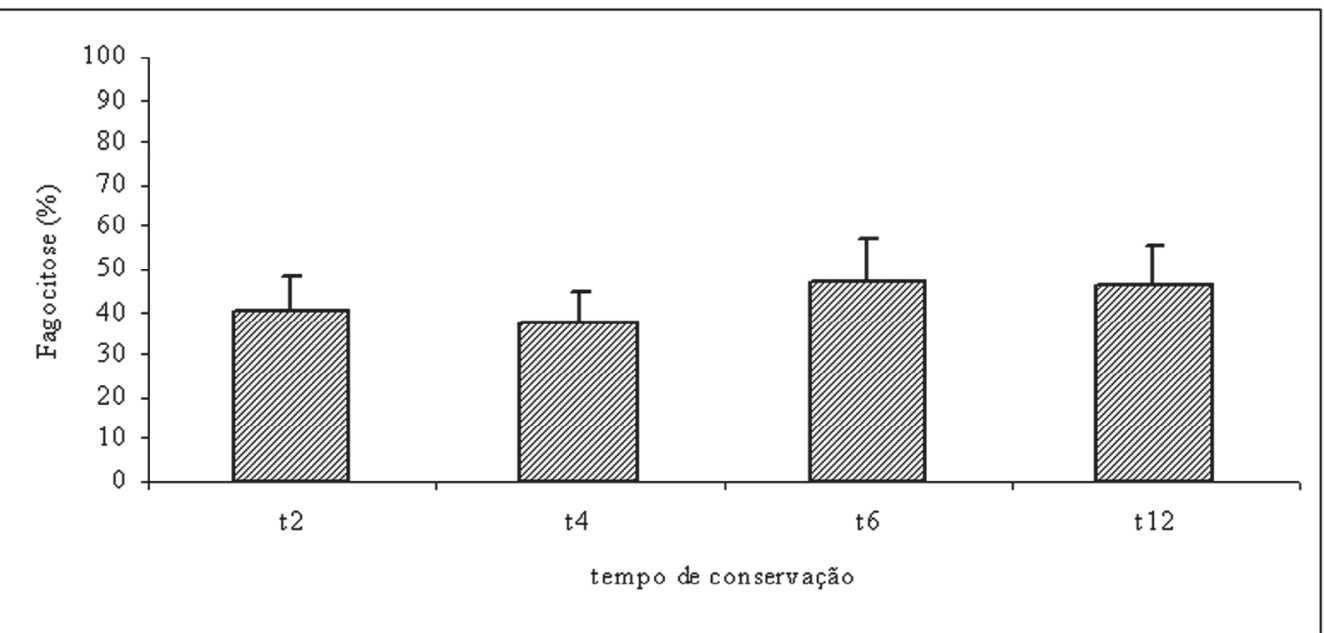

Figura 5 - Percentual de PMN do sangue de bezerros em atividade de fagocitose para a E.coli marcada pelo Texas Red, segundo o tempo em que as amostras foram mantidas em gelo, São Paulo, 2006

fluorescência está associada ao número de bactérias fagocitadas, entretanto, parece pouco provável que este fato tenha ocorrido, pois isto poderia acarretar um maior estímulo ao metabolismo oxidativo celular o que não foi observado neste estudo.

A menor magnitude dos valores obtidos tanto para o metabolismo oxidativo quanto para a fagocitose no tempo t12 e a impossibilidade de avaliação das amostras no tempo t24, são concordantes com Weiss ${ }^{2}$ que afirma que o processo de conservação das amostras é um ponto chave na obtenção de resultados precisos; células danificadas ou mortas apresentam alterações nos gráficos de "Dot-Plot" no que se refere ao tamanho, granulosidade e inespecificidade de ligação a anticorpos monoclonais.

Kampen et al. ${ }^{15}$, avaliando a estabilidade e a repetibilidade da fagocitose e do metabolismo oxidativo de PMN do sangue de bovinos, por citometria de fluxo, utilizando o Phagotest (E. coli marcada com FITC) e o Bursttest (E.coli) e mais três métodos clássicos de avaliação funcional destas células, verificaram que não houve diferenças entre os métodos clássicos e os de citometria de fluxo no que se refere à estabilidade dos mesmos. Os resultados deste trabalho foram expressos em relação ao percentual de células que realizaram fagocitose de todos os animais estudados durante o período $(69,6 \%$ e d.p. $=14,4)$, não mostrando se ocorreram variações da média geométrica da intensidade de fluorescência destas células.

Em relação ao tempo de análise, Jain, Paape e Miller ${ }^{5}$, utilizando a citometria de fluxo para contagem diferencial de leucócitos de 50 vacas holandesas de amostras de sangue colhidas em EDTA estocadas em gelo e processadas dentro de 6 horas, verificaram que a contagem de leucócitos totais no citômetro foi menor que a obtida 
em sistemas automatizados $(4.660 \pm 2.143$ / ul vs 10.209土4.153).

Finalmente, os resultados deste trabalho poderiam ter sido afetados pelo uso de heparina na colheita das amostras de sangue. Carter et al. ${ }^{16}$ avaliaram o uso de três anticoagulantes em amostras recém-colhidas e após 24 horas, além da ocorrência de morte celular evidenciada através da incubação destas células com Iodeto de Propídeo (PI). Nas amostras recém-colhidas, não houve diferença estatística relacionada ao número de granulócitos marcados por PI, entretanto a avaliação destas células, após 24 horas em temperatura ambiente, mostrou que as amostras com EDTA apresentaram um aumento significativo do número de granulócitos positivos para PI. A morte celular foi evidenciada nas amostras com ACD (ácido citrato dextrose) e irrelevante naquelas com heparina. O trabalho de Ducusin et al. ${ }^{7}$, sobre a atividade de fagocitose de leucócitos PMN de bovinos para partículas fluorescentes em diferentes condições de incubação (tempo e temperatura), usando diferentes estímulos (LPS, PMA, fMLP e citocalisina B) e diferentes anticoagulantes (heparina, ACD e EDTA) em amostras analisadas dentro de cinco horas após a colheita do sangue, mostraram que a heparina ainda é o anticoagulante de escolha para a fagocitose.
Em contrapartida, Erduran et al. ${ }^{17}$, verificaram apoptose dos neutrófilos após uma hora de ensaio quando usadas doses altas de heparina $(20 \mathrm{U} / \mathrm{ml})$.

\section{Conclusões}

Após a análise dos dados encontrados neste trabalho, pode-se concluir que o tempo ideal para análise do metabolismo oxidativo basal e induzido é de até duas horas após a colheita do material, quando o mesmo é conservado em banho de gelo. Após o período de 4 horas, os resultados mostraram não haver diferenças entre o metabolismo basal e o induzido, devendo-se, portanto, evitar a análise do metabolismo oxidativo utilizando a E.coli como estímulo, após este período de tempo, em se tratando da espécie bovina. Em relação à fagocitose, são necessários maiores estudos a fim de se verificar a influência do tempo na intensidade de fluorescência quando da utilização da Escherichia coli, nessa mesma espécie animal.

\section{Agradecimento}

À Instituição Patrocinadora, Fundação de Amparo à Pesquisa do Estado de São Paulo - FAPESP, pelo suporte financeiro (Processo: 05/50548-6).

\section{Effect of conservation time on bovine polymorphonuclear leukocytes in calves blood on oxidative burst and Escherichia coli phagocytosis activity}

\begin{abstract}
The time effect on oxidative burst and phagocytosis of Eschericbia coli by polymorphonuclear leukocytes of 5 healthy calve blood samples were evaluated. Samples were kept on ice bath for two (t2), four ( $\mathrm{t} 4)$, six ( $t 6$ ), twelve (t12) and 24 hours ( $\mathrm{t} 24)$ before the tests. The oxidative burst was measured using the 2',7'-dichlorfluorescein-diacetate (DCFH-DA) and E.coli as stimulus, also the same bacteria was used to phagocytosis process. The PMN basal oxidative burst of calves blood samples were analyzed by flow cytometry and were higher at times $t 4, t 6$ and $t 12(p<0,05)$ than at $t 2$. The oxidative burst fluorescence intensity induced by bacteria was higher at the times $t 4$ and $t 6$ than at $t 2(p<0,05)$. The comparison between the basal oxidative burst and the one induced by bacteria on each time, showed $t 2$ time as the one with the highest difference, with geometric media and standard
\end{abstract}

Key words:

Phagocytosis.

Oxidative metabolism. Conservation time. Bovine.

Escherichia coli. 
deviation of $18,3 \pm 4,4$ and $26,7 \pm 1,8(\mathrm{p}<0,05)$, respectively. Phagocytosis activity was measured by fluorescence intensity and was higher on samples kept on ice bath for 6 hours than those at $t 2$, t4 and $12(\mathrm{p}<0,05)$. The phagocytosis percentage did not differ between the different times. The ideal time to test the oxidative burst was 2 hours (t2). Further researches are necessary to verify the conservation time influence on E.coli phagocytosis by PMN of bovine blood.

\section{Referências}

1 NAKAGE, A. P. M. et al. Metodologia e aplicação da citometria de fluxo na hematologia veterinária. Ciência Rural, v. 35 n. 4, p. 966-973, 2005.

2 WEISS, D. J. Application of flow cytometric techniques to veterinary clinical hematology. Veterinary Clinical Pathology, v. 31, n. 2, p. 72-82, 2002.

3 PARASKEVAS, F. Clinical Flow Cytometry. In: LEE, G. R. et al. Wintrobe's clinical hematology. $10^{\text {th }} \mathrm{ed}$. Philadelphia: Lippincott Willians \& Wilkins. 1999. p. 56-71.

4 VUORTE, J.; JANSSON, S. E.; REPO, H. Evaluation of red blood cell lysing solutions in the study of neutrophil oxidative burst by the DCFH assay. Cytometry, v. 43, n. 4, p. 290-296, 2001.

5 JAIN, N. C.; PAAPE, M. J.; MILLER, R. H. Use of flow cytometry for determination of differential leukocyte counts in bovine blood. American Journal of Veterinary Research, v.52, n.4, p. 630-636, 1991.

6 VAN OOSTVELDT, K. et al. Respiratory burst activity in activated and unstimulated isolated bovine blood neutrophils during experimentally induced Escherichia coli mastitis, Journal of Dairy Research, v. 66, n. 3, p. 375-383, 1999.

7 DUCUSIN, R. J. T. et al. Phagocytic response of bovine polymorphonuclear leukocytes to different incubation conditions and following exposure to some effectors of phagocytosis and different anticoagulants in vitro. The Canadian Journal of Veterinary Research, v. 65, n. 1, p. 38-44, 2001.

8 SILVA, F. R. Efeitos de benzodiazepínicos sobre a atividade de neutrófilos de ratos avaliados por citometria de fluxo. 2003. $179 \mathrm{f}$. Tese (Doutorado em Patologia Experimental e Comparada) - Faculdade de Medicina Veterinária e Zootecnia, Universidade de São Paulo, São Paulo, 2003.

9 MASSOCO-SALLES GOMES, C. O. Receptores benzodiazepínicos periféricos e a resposta imune inata de eqüinos: efeito do midazolam. 2003. 125 f. Tese
(Doutorado em Patologia Experimental e Comparada) Faculdade de Medicina Veterinária e Zootecnia, Universidade de São Paulo, São Paulo, 2003.

10 HASUI, M.; HIRABAYASHI, Y.; YOHNOSUKE, K. Simultaneous measurement by flow cytometry of phagocytosis and hydrogen peroxide production of neutrophils in whole blood. Journal of Immunological Methods, v. 117, n. 1, p. 53-58, 1989.

11 GREGORI, G.; RAGHEB, K.; ROBINSON, J. P. Introduction to WinMDI (J. Trotter 1993-1998) for the analysis of flow cytometry listmode data files. Version 2.2. Purdue University Cytometry Laboratories. Disponível em: <http://www.cyto.purdue.edu > . Acesso em: 10 jun. 2006.

12 BERQUÓ, E. S.; SOUZA, J. M. P.; GOTLIEB, S. L. D. Bioestatística. 2. ed. São Paulo: E.P.U., 1981.

13 STATSDIRECT LTD. StatsDirect statistical software version 2.5.8, Disponível em: < http:// statsdirect.com >. Acesso em: 8 jan. 2007.

$14 \mathrm{ZHAO}$, J. et al. Respiratory burst activity of polymorphonuclear cells is dependent on the cell preparation technique. Acta Anaesthesiologica Scandinavica, v. 47, n. 6, p. 702-706, 2003.

15 KAMPEN, A. H. et al. Repeatability of flow cytometric and classical measurement of phagocytosis and respiratory burst in bovine polymorphonuclear leukocytes. Veterinary Immunology and Immunopathology, v. 97, n. 1-2, p. 105-114, 2004.

16 CARTER, P. H. et al. Flow cytometric analysis of whole blood lysis, three anticoagulants, and five cell preparations. Cytometry, v. 13, n. 1, p. 68-74, 1992. Disponível em:<http://www3.interscience.wiley.com/ cgi-bin/fulltext/110427662/PDFSTART > . Acesso em: 14 jan. 2007.

17 ERDURAN, E. et al. Apoptotic effects of heparin on lymphoblasts, neutrophils, and mononuclear cells: results of a preliminary in vitro study. American Journal of Hematology, v. 61, n. 2, p. 90-93, 1999. Disponível em: < http://www3.interscience.wiley.com/cgi-bin/ fulltext/62000069/PDFSTART $>$. Acesso em: 14 jan. 2007. 